\title{
Compaction and Plasticity Comparative Behaviour of Soft Clay Treated with Coarse and Fine Sizes of Ceramic Tiles
}

\author{
Mohammed Ali Mohammed Al-Bared ${ }^{1}$, Aminaton Marto ${ }^{2,3, *}$, Indra Sati Hamonangan \\ Harahap $^{1}$, and Fauziah Kasim ${ }^{3}$ \\ ${ }^{1}$ Department of Civil and Environmental Engineering,Universiti Teknologi PETRONAS , 32610 \\ Perak, Malaysia \\ ${ }^{2}$ Disaster Preparedness and Prevention Centre, Malaysia-Japan International Institute of Technology, \\ Universiti Teknologi Malaysia (UTM) Kuala Lumpur, 54100 Kulala Lumpur, Malaysia \\ ${ }^{3}$ Faculty of Civil Engineering, Universiti Teknologi Malaysia, 81310 UTM Johor Bahru, Johor, \\ Malaysia
}

\begin{abstract}
Recycled blended ceramic tiles (RBT) is a waste material produced from ceramic tile factories and construction activities. RBT is found to be cost effective, sustainable, environmental-friendly and has the potential to be used as an additive in soft soil stabilization. Recent reports show that massive amounts of RBT are dumped into legal or illegal landfills every year consuming very large spaces and creating major environmental problems. On the other hand, dredged marine clay obtained from Nusajaya, Johor, Malaysia has weak physical and engineering characteristics to be considered as unsuitable soft soil that is usually excavated, dumped into landfills and replaced by stiff soil. Hence, this study investigates the suitability of possible uses of RBT to treat marine clay. Laboratory tests included Standard proctor tests and Atterberg limits tests. The plasticity of marine clay was evaluated by adding $10 \%, 20 \%$, $30 \%$ and $40 \%$ of $0.3 \mathrm{~mm} \mathrm{RBT}$. In addition, the compaction behaviour of treated marine clay was compared by adding two different sizes $(0.3 \mathrm{~mm}$ and $1.18 \mathrm{~mm}$ diameter) of RBT. For both coarse and fine sizes of RBT, $10 \%, 20 \%, 30 \%$ and $40 \%$ of the dry weight of the soft clay were added. The mixture of each combination was examined in order to evaluate the Maximum Dry Density (MDD) and the optimum moisture content (OMC) for the treated soft clay. MDD and OMC for soft untreated samples were $1.59 \mathrm{Mg} / \mathrm{m}^{3}$ and $22 \%$, respectively. Treated samples with $10 \%, 20 \%, 30 \%$ and $40 \%$ of $0.30 \mathrm{~mm}$ size RBT resulted in a significant reduction of OMC ranged from 19 to $15 \%$ while MDD resulted in increment ranged from 1.69 to $1.77 \mathrm{Mg} / \mathrm{m}^{3}$. In addition, samples treated with $10 \%, 20 \%, 30 \%$ and $40 \%$ of $1.18 \mathrm{~mm}$ size RBT resulted in major reduction of OMC ranged from 15 to $13.5 \%$ while MDD increased effectively from 1.75 to 1.82 $\mathrm{Mg} / \mathrm{m}^{3}$. For all mix designs of soft clay-RBT, MDD was gradually increasing and $\mathrm{OMC}$ was sharply reducing with further increments of both sizes of RBT.
\end{abstract}

\footnotetext{
* Corresponding author: aminaton@,utm.my
} 


\section{Introduction}

Continuous and fast development in construction industry reduces the natural available resources and induced pollutions to land, water and air. The necessity to provide alternatives to natural resources is the concern of recent research in civil engineering. Fast development in civil engineering projects resulted in a corresponding reduction in allnatural resources such as lands that force engineers and contractors to seek alternatives. One of the available options is the construction of buildings and other engineering structures on soft soils, which are weak and problematic in nature and they are not capable to sustain the imposed load of the sub and super structures of the buildings [1]. According to [2-4], soft soil is associated with high settlement and instability, low permeability and shear strength, high plasticity, and high-water content. Moreover, the major problem that makes soft soil unsuitable to be a foundation soil for construction is its swell-shrink behavior. Soft soil swells when it gains water content and shrinks when water is dried out [5]. Various kinds of cracks induced by excessive settlement may appear on railways, highways and other engineering structures founded on soft soils due to the swell-shrink phenomenon during wet and dry seasons $[6,7]$. Besides, soft soils are very sticky when they are wet and hard to very hard when they are dry which make it difficult to be compacted [6]. The defects and the damages of roads and engineering structures caused by the soft soil associated problems require high budgets to repair. Therefore, seeking solutions to soft soil problems have been studied by many researchers.

Recently, wide ranges of chemical stabilization additives are implemented in ground stabilization. Traditional and non-traditional chemical additives resulted in significant improvements of soft soil. Lime, cement, calcium carbide and fly ash are examples of the chemical additives adopted successfully in soft soil improvements [8-12]. However, from environmental prospective, chemical additives are generally classified as nonenvironmental friendly, expensive and require advanced instrumentation during application at site. Besides, underground water contamination is an example of the several problems created by the implementation of chemical additives in soft soil improvement. On the other hand, ceramic tiles factories have high quantity of wastes during production ranged from $7 \%-30 \%$ reported by various prominent researchers $[13,14]$. This powered waste usually accumulate in lands near to the factory area and by the effect of atmosphere, it becomes dried and carried by the wind. Ceramic dust transportation by wind helps to spread the waste that affects the health of human beings as well as causing environmental problems. Furthermore, those cracked, smashed, or broken tiles at the construction sites are not accepted for installation that end up as a waste [15]. Utilizing recycled materials in soil stabilization is an alternative way that promotes a sound environment [16].

Soil stabilization by compaction is one of the widely used mechanical methods adopted by many researchers all over the globe. Soil compaction can be described as increasing the particle density of the soil and decreasing the air spaces within the particles at constant water content. This will increase the shear strength and decrease the associated settlement of the compacted soil as it becomes in an impermeable state [17]. Compaction methods differ between cohesive and cohesionless soils. Sheep foot compactor can be used to compact cohesive soils as it contains sufficient amounts of silt and clay that make it in an impermeable state when compacted properly. While cohesionless soils need a vibrating compacter for compaction as it contains sand and gravel [18].

Hence, this research is aimed to treat soft soil with an environmental, sustainable and economical additive that is still not widely investigated in this area of research. Recycled blended ceramic tiles (RBT) are introduced in this study as an environmental additive to be used in soil stabilization. The influence of different percentages and sizes of RBT on plasticity and compaction behavior of marine clay is assessed. 


\section{Materials}

\subsection{Marine clay}

Marine clay is the soil being investigated in this study, due to its insufficient strength and poor engineering properties. This soil is usually excavated, transported and dumped into legal and illegal landfills as a waste material and then replaced at site by a stiff soil that has the minimum requirements to sustain the construction loads. Dredged marine clay was collected from Kota Iskander, Nusajaya, Johor, Malaysia to be studied and tested. It was collected from a depth of one meter and it was in wet condition with natural moisture content of 59\%. The disturbed soil was transported to the laboratory and exposed to room temperature until it dried thoroughly. Fig. 1 shows the location of the sampling site of the marine clay.
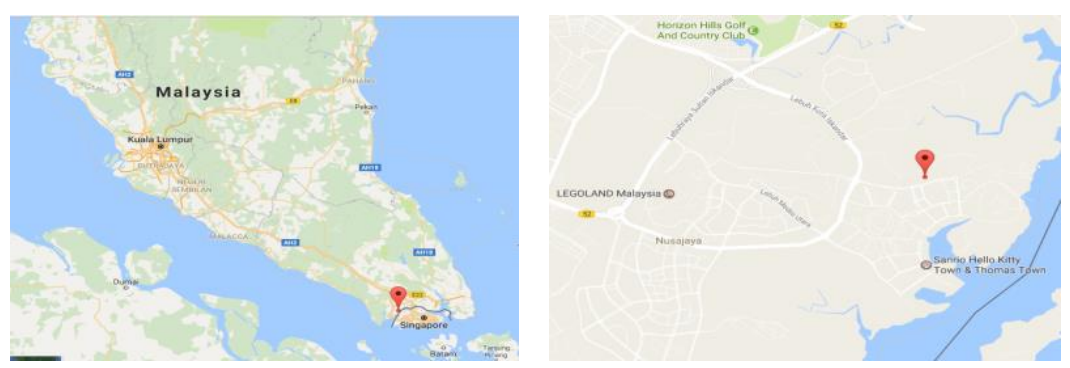

Fig. 1. Location of the site from which marine clay was collected.

When the marine clay reached to the laboratory, it was naturally dried, grinded and sieved for compaction tests. Soil was first oven dried at $105^{\circ} \mathrm{C}$ for 24 hours to make sure the soil has zero water content before testing. To obtain the physical properties of marine clay, sieved samples were used for the specific gravity test, the compaction test, the Atterberg limits tests, the organic test and the natural moisture content test. All basic tests were conducted in accordance with BSI 1377, Part 2: 1990 [19]. The average values of all the physical tests conducted on marine clay are demonstrated in Table 1. According to Wong et al. [17], soils that have an organic content of less than $10 \%$ are considered inorganic. Therefore, the tested marine clay is considered as inorganic soil. Moreover, based on the results of liquid limit and plasticity index and in accordance with [20], and by referring to the plasticity chart, the soil is classified as CLAY with intermediate plasticity. It is given the group symbol CI.

Table 1. Physical characteristics of untreated marine clay.

\begin{tabular}{|l|c|c|}
\hline \multicolumn{1}{|c|}{ Soil properties } & Standard & Average value \\
\hline Natural moisture content (\%) & BS 1377-1 & 59 \\
\hline Specific gravity $\left(\mathrm{G}_{\mathrm{s}}\right)$ & BS 1377-2 & 2.52 \\
\hline Organic contents (\%) & & 2.74 \\
\hline Atterberg limits & & \\
\hline Liquid limit $(\%)$ & BS 1377-1 & 41 \\
\hline Plastic limit (\%) & BS 1377-1 & 22 \\
\hline Plasticity index (\%) & BS 1377-1 & 19 \\
\hline Proctor test & & \\
\hline Optimum moisture content $(\%)$ & BS 1377-4 & 22 \\
\hline Maximum dry density $\left(\mathrm{kg} / \mathrm{m}^{3}\right)$ & BS $1377-4$ & 1590 \\
\hline
\end{tabular}




\subsection{Recycled ceramic tiles (RBT)}

RBT in this research refers to the wastage of ceramic tile that is blended into fine and coarse powder to be used for the stabilization of the marine clay. Taman Ponderosa, Impian Heights Golf and Country Club and Taman Pelangi, Johor were the construction sites from which RBT was collected to be utilized in this research. Prior to RBT collection, an investigation was made to check on the availability of RBT wastage in those specific construction sites. Meanwhile, presence of cracks and smashes on the surface of new tiles delivered to construction sites and design problems / failures are the main reason for the high amount of tiles wastages at construction sites. This is due to the improper handling, casing, low quality and shaking during transportation. Tiles collected for this research are those that has been rejected at sites as well as those been hacked for renovation activities. Besides, the wastage produced by cutting tiles into exact sizes at site. The ceramic tiles used in this research were prepared in several steps started by grouping them into different groups based on colour and type. The major group of ceramic tile waste was cleaned to remove cement, dust and other substances stick on it. Then, the tiles were manually crashed into smaller pieces using hammer in order to be able to fit into the crushing machine. The crushing machine was used to obtain RBT of $5 \mathrm{~mm}$ size. Next, the $5 \mathrm{~mm}$ sized RBT were transferred into Los Angeles Abrasion machine in order to blend it into powder and this process took almost 24 hours. The period of time was chosen to be 24 hours only in order to obtain a powder that has a mixture of coarse and fine content. After that, tiles were sieved using $1.18 \mathrm{~mm}$ and $0.3 \mathrm{~mm}$ sieve meshes. The powder that passed $1.18 \mathrm{~mm}$ sieve and retained on $0.3 \mathrm{~mm}$ sieve was used as $1.18 \mathrm{~mm}$ sized RBT. While the powder that passed $0.3 \mathrm{~mm}$ sieve and retained on the pan was used as $0.3 \mathrm{~mm}$ sized RBT. For both sizes of RBT, a mix design of $10 \%, 20 \%, 30 \%$, and $40 \%$ of the dry weight of marine clay was used in this study. This mix design was chosen based on previous study that used almost similar quantities of ceramic waste to replace Portland cement in concrete [21].

\subsection{Samples preparation for standard proctor compaction tests}

Sample preparation for all proctor tests followed the BSI 1377: Part 4: 1990 [22] for all the methods and procedures implemented. The compaction tests were performed in order to obtain the density-moisture relationships for various mix designs of RBT stabilized marine clay. These tests measure the maximum dry density and optimum moisture content of the untreated and the treated marine clay. In order to conduct the compaction tests, approximately $90 \mathrm{~kg}$ of untreated marine clay was oven dried at $105^{\circ}-110^{\circ} \mathrm{C}$ for 24 hours and stored in air tight containers. Prior to preparing the admixture of marine clay and RBT, marine clay was sieved through $2 \mathrm{~mm}$ sieve mesh for the purpose of removing coarse particles, plants and roots. First series of tests were conducted for natural marine clay in order to determine its compaction parameters. Then, sieved marine clay was mixed with the predetermined amount of RBT before mixing with water. The admixture of marine clay and RBT was mixed thoroughly with water until uniform color was achieved. The mixture was kept in an air tight plastic bag for minimum 24 hours in order for the moisture to be well distributed. To perform the test, the admixture was transferred into the compaction mold (115.5 mm height and $105 \mathrm{~mm}$ diameter) that was attached to a removable base plate prior to weight measurement. Before the admixture was placed, a detachable steel extension collar was installed at the top of the compaction mold. The admixture was placed inside the compaction mold in three equal layers and compacted 27 blows for each layer using $2.5 \mathrm{~kg}$ steel rammer. After the three layers were compacted, the extension top part of the mold was dismantled and the admixture was cut to remove the excess marine clay-RBT admixture. A digital balance was used to weigh the admixture of marine clay-RBT together with the 
mold and the weight was recorded to the nearest three decimal places. In order to determine the moisture content of the mix, two samples were collected from the top and bottom of the compacted admixture. The same procedures were repeated five times in order to be able to draw a proper compaction curve.

\subsection{Sample preparation for Atterberg limits tests}

The physical properties of the combination of RBT and marine clay were assessed by conducting liquid limit and plastic limit tests. Sample preparation started by sieving the untreated marine clay through $0.425 \mathrm{~mm}$ sieve mesh. Due to the large size of $1.18 \mathrm{~mm}$ RBT, only $0.3 \mathrm{~mm}$ RBT could be used for Atterberg limit tests. The soil was air dried and mixed with various mix designs $(10 \%, 20 \%, 30 \%$ and $40 \%)$ of $0.3 \mathrm{~mm}$ RBT. The mixture of marine clay and RBT was mixed with water and kept in an airtight plastic bag for a minimum of 24 hours. The liquid limit and plastic limit tests were then conducted using the cone penetrometer method in accordance with the BSI 1377: Part 2: 1990 [19].

\section{Results and discussions}

\subsection{Atterberg limits results}

The results of liquid limit, plastic limit and plasticity index for marine clay and $0.3 \mathrm{~mm}$ RBT treated marine clay are presented in Table 2. It can be observed that $0.3 \mathrm{~mm}$ RBT was able to decrease the plasticity index of the soil. Besides, increments of $0.3 \mathrm{~mm}$ RBT resulted in decreasing the plasticity index as it was expected [23-25]. The reduction in the value of plasticity index with the increments of RBT is due to the replacement of marine clay fine particles with RBT coarse particles. Comparison between the effect of RBT and palm oil fuel (POFA) as studied by [26] showed that both waste materials were able to decrease the plasticity of the stabilized soft soil. As shown in Fig. 2 (Left), the liquid limit of marine clay decreased sharply from $40.4 \%$ to $32.5 \%$ when only $10 \%$ of $0.3 \mathrm{~mm}$ RBT was added. Further increments in the percentage of $0.3 \mathrm{~mm}$ RBT (20-40\%) decreased the liquid limit of marine clay. In addition, as shown in Fig. 2 (Right) the plastic limit of treated marine clay also reduced when $0.3 \mathrm{~mm}$ RBT was added. Further increments of 0.3 mm RBT resulted also in decreasing the plastic limit [27]. The reduction trend of both liquid limit and plastic limit resulted in decreasing the plasticity index of marine clay as shown in Fig. 3. The plasticity of marine clay reduced significantly when $0.3 \mathrm{~mm}$ RBT was added. Meanwhile, $0.3 \mathrm{~mm}$ RBT was able to reduce the plasticity of marine clay from intermediate plasticity to low plasticity when $40 \% 0.3 \mathrm{~mm}$ RBT was added. It is also found that the effect of $0.3 \mathrm{~mm}$ RBT depends on its percentage. When the percentage increases, further reduction in the plasticity index is achieved.

Table 2. Atterberg limit results for $0.3 \mathrm{~mm}$ RBT treated marine clay.

\begin{tabular}{|c|c|c|c|c|}
\hline Type & $0.3 \mathrm{~mm}$ RBT (\%) & Liquid limit (\%) & Plastic limit (\%) & Plasticity index (\%) \\
\hline Marine clay & 0 & 40.4 & 21.83 & 18.57 \\
\hline Marine clay - RBT & 10 & 32.5 & 18.51 & 13.99 \\
\hline Marine clay - RBT & 20 & 30.1 & 17.45 & 12.65 \\
\hline Marine clay - RBT & 30 & 28.6 & 16.98 & 11.58 \\
\hline Marine clay - RBT & 40 & 25.9 & 15.33 & 10.57 \\
\hline
\end{tabular}

Moreover, the statistical observation of the results obtained by the addition of different mix designs of $0.3 \mathrm{~mm}$ RBT is expressed in Figs. 2 and 3. It is shown clearly that the value 
of Coefficient of determination $\left(\mathrm{R}^{2}\right)$ ranged between 0.87 and 0.90 that means the inconsistency in the linearity of the achieved results is very insignificant. This confirms an appropriate interpretation of $0.3 \mathrm{~mm}$ RBT mix designs.
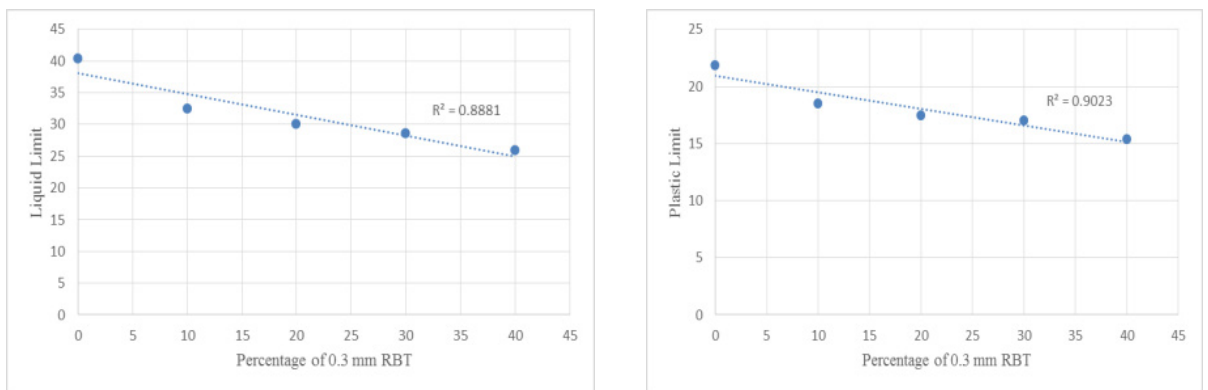

Fig. 2. Liquid limit (Left) and plastic limit (Right) of RBT treated marine clay at various mix designs.

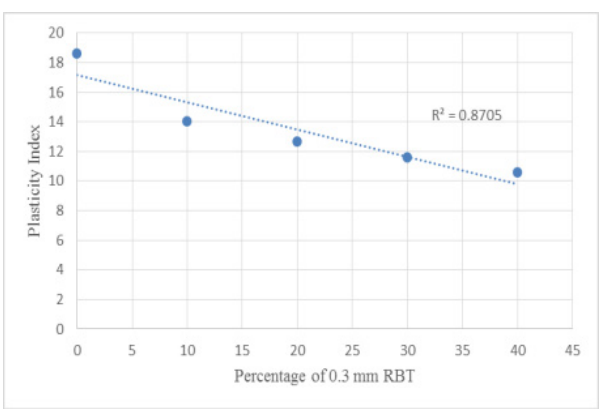

Fig. 3. Plasticity index of RBT treated marine clay at various mix designs.

\subsection{Influence of RBT on compactability}

The results of the maximum dry density (MDD) and the optimum moisture content (OMC) of untreated marine clay, $0.3 \mathrm{~mm}$ and $1.18 \mathrm{~mm}$ RBT treated marine clay are shown in Table 3. The results clearly showed continuous increases of MDD and continuous decreases in OMC as the percentage of RBT was increased from $10 \%$ to $40 \%$. The reason of the increments of MDD can be explained due to the replacement of RBT particles of high specific gravity (2.57) with marine clay particles of low specific gravity (2.52). Whereas the reduction in OMC is due to the reduction of attraction for water molecules after the RBT particles are substituted with soil particles.

Table 3. Standard Proctor compaction test results of RBT treated marine clay.

\begin{tabular}{|c|c|c|c|c|}
\hline Type & $\begin{array}{c}\text { RBT size } \\
(\mathrm{mm})\end{array}$ & $\begin{array}{c}\text { RBT percentage } \\
(\%)\end{array}$ & $\begin{array}{c}\text { Optimum } \\
\text { moisture content } \\
(\mathrm{OMC})(\%)\end{array}$ & $\begin{array}{c}\text { Maximum dry } \\
\text { density (MDD) } \\
\left(\mathrm{Mg} / \mathrm{m}^{3}\right)\end{array}$ \\
\hline Marine clay & - & - & 22 & 1.59 \\
\hline Marine clay - RBT & 0.3 & 10 & 19 & 1.69 \\
\hline Marine clay - RBT & 0.3 & 20 & 16.7 & 1.76 \\
\hline Marine clay - RBT & 0.3 & 30 & 16.5 & 1.75 \\
\hline Marine clay - RBT & 0.3 & 40 & 15 & 1.77 \\
\hline Marine clay - RBT & 1.18 & 10 & 15 & 1.75 \\
\hline Marine clay - RBT & 1.18 & 20 & 15 & 1.78 \\
\hline Marine clay - RBT & 1.18 & 30 & 14 & 1.8 \\
\hline Marine clay - RBT & 1.18 & 40 & 13.5 & 1.82 \\
\hline
\end{tabular}


Fig. 4 shows the compaction curves of both $1.18 \mathrm{~mm}$ and $0.3 \mathrm{~mm}$ RBT treated marine clay. As can be seen in Fig. 4 (Left), addition of $1.18 \mathrm{~mm}$ RBT increased the MDD from $1.59 \mathrm{Mg} / \mathrm{m}^{3}$ to $1.82 \mathrm{Mg} / \mathrm{m}^{3}$, whereas OMC was reduced from $22 \%$ to $13.5 \%$ at $40 \% \mathrm{RBT}$. Besides, as can be seen in Fig. 4 (Right), the addition of $0.3 \mathrm{~mm}$ RBT increased the MDD from $1.59 \mathrm{Mg} / \mathrm{m}^{3}$ to $1.77 \mathrm{Mg} / \mathrm{m}^{3}$, while decreased the OMC from $22 \%$ to $15 \%$ at $40 \%$ RBT. The additions of RBT reduced the affinity of soil for water molecules and thus decreased the OMC. This was in agreement with $[24,25]$ who used ceramic tiles waste to treat soft soil. The influence of RBT on the compactability of soft soil can be compared to that achieved with the treatment using POFA. The addition of POFA to stabilize soft soil resulted in increasing MDD and decreasing OMC [26]. However, the addition of POFA without an additional binder such as cement or lime did not result in significant improvement of soft soil $[26,28]$.
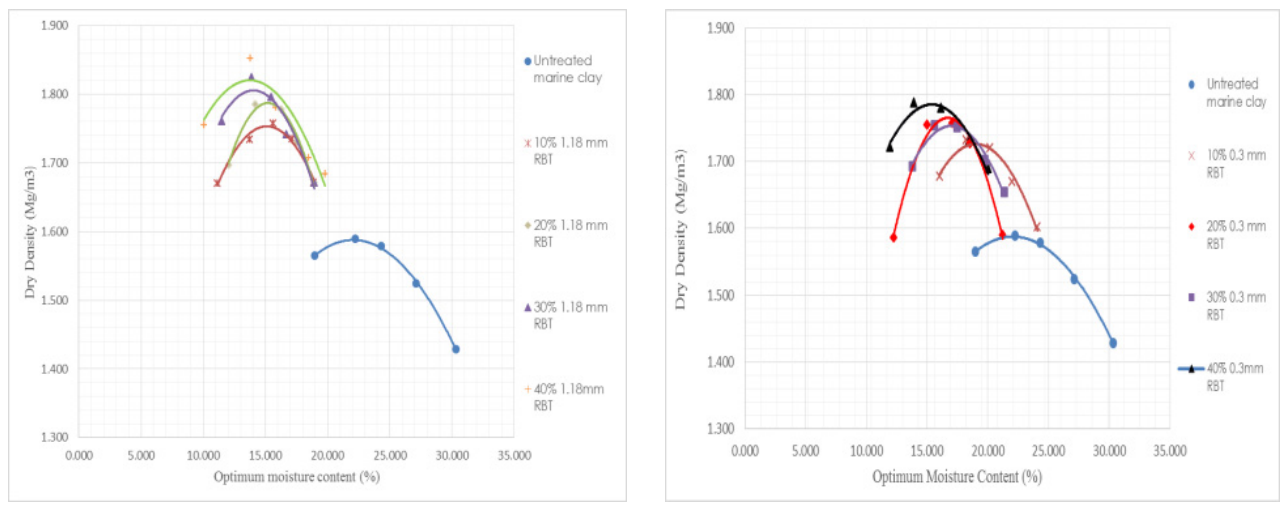

Fig. 4. Compaction behaviour of untreated and treated marine clay with different mix designs of 1.18 $\mathrm{mm}$ RBT (Left) and $0.3 \mathrm{~mm}$ RBT (Right).

\subsubsection{Comparing the effect of RBT size}

Fig. 5 (left) illustrates a comparative analysis of MDD for $0.3 \mathrm{~mm}$ and $1.18 \mathrm{~mm}$ RBT treated marine clay. It is clearly seen that $1.18 \mathrm{~mm}$ RBT resulted in higher MDD compared to $0.3 \mathrm{~mm}$ RBT that is due to bigger particle size. The $1.18 \mathrm{~mm}$ RBT was coated by the clay particles creating large size aggregate that occupied bigger area. Thus, the MDD was increased significantly and this is an indication of improvement of marine clay properties [26]. In addition, Fig. 5 (right) shows an analysis of OMC results of both sizes of RBT and it can be seen the lowest value of OMC was obtained at $40 \% 1.18 \mathrm{~mm}$ RBT. The larger the size of RBT, the lower the moisture content [29]. Furthermore, the statistical observation obtained by adding $10 \%, 20 \%, 30 \%$ and $40 \%$ of $0.3 \mathrm{~mm}$ and $1.18 \mathrm{~mm}$ RBT is expressed in Fig. 5. The coefficient of determination had a value of $\mathrm{R}^{2}$ ranged between 0.91 and 0.67 that indicates insignificant discrepancy in the linearity of the achieved results. This confirms suitable interpretation of RBT mix designs. 

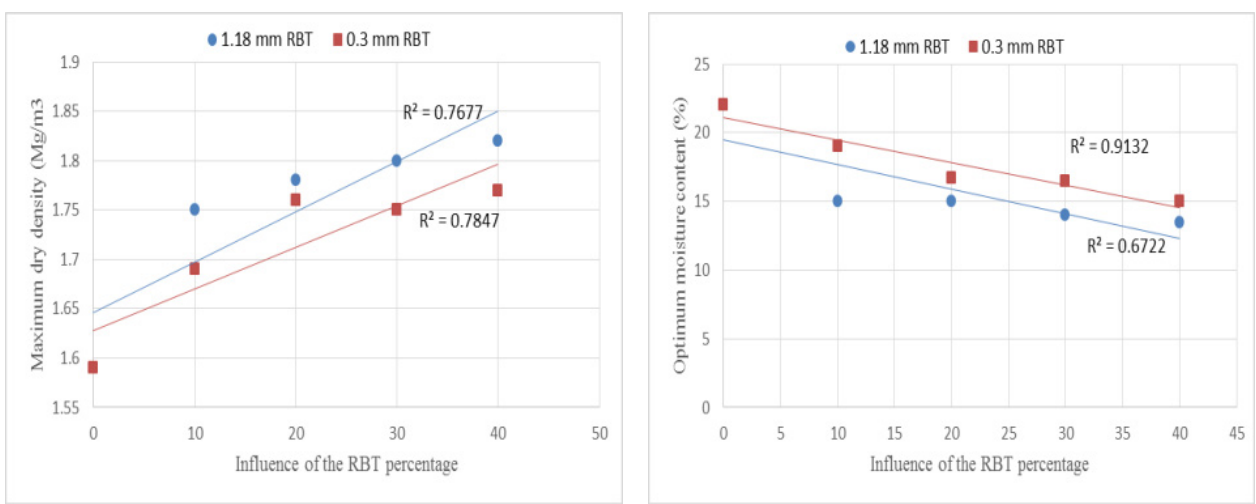

Fig. 5. Effect of various RBT mix designs on the MDD (Left) and OMC (Right) of marine clay.

\section{Conclusions}

The investigation of using ceramic tiles in soft soil stabilization was for the purpose of achieving the status of green technology, cleaner production and economical approaches. A series of laboratory tests were conducted to evaluate and check the suitability of recycled blended ceramic tiles (RBT) on treating marine clay. The tests included liquid limit, plastic limit, plasticity index, and compaction parameters. The following conclusions can be drawn; 1 . A decreasing trend of liquid limit, plastic limit and plasticity index was observed with increasing amount of $0.3 \mathrm{~mm}$ RBT. The plasticity of the marine clay was reduced from intermediate plasticity to low plasticity at $40 \% 0.3 \mathrm{~mm}$ RBT. 2. Additions of both sizes of RBT increased the MDD and decreased the OMC of the marine clay significantly. 3. In terms of size influence, $1.18 \mathrm{~mm}$ RBT was more effective than $0.3 \mathrm{~mm}$ RBT that act as a strengthening agent that bonded the marine clay particles together resulting in higher density and lower moisture content. The larger the size of RBT, the more effective the compaction parameters of the treated marine clay.

The authors would like to express their gratitude to UTP for the generous support given for the publication of this paper using the Graduate Assistantship Scheme. Besides, the authors express their gratitude to the Research University Grant Scheme Q.J130000.2522.16H04 from UTM.

\section{References}

1. Y. Cai, B. Shi, C.W.W. Ng, C. sheng Tang, Eng. Geol. 87 (2006)

2. M.A.M. Al-Bared, A. Marto, Proc. 2nd Int. Conf. Sep. Technol. 2017 Rev. (2017)

3. J.S. Yadav, S.K. Tiwari, J. Build. Eng. 9 (2017)

4. Y. Yi, L. Gu, S. Liu, Appl. Clay Sci. 103 (2015)

5. S. Vichan, R. Rachan, 53 (2013)

6. A. Mahamedi, M. Khemissa, Hous. Build. Natl. Res. Cent. J. 11 (2014)

7. L.C. Dang, B. Fatahi, H. Khabbaz, Procedia Eng. 143 (2016)

8. N. Yoobanpot, P. Jamsawang, S. Horpibulsuk, Appl. Clay Sci. 141 (2017)

9 V. Anggraini, A. Asadi, B.B.K. Huat, H. Nahazanan, Measurement 59 (2015)

10. A. Zukri, Procedia Eng. 53 (2013)

11. R.K. Etim, A.O. Eberemu, K.J. Osinubi, Transp. Geotech. 10 (2017)

12. T.-C. Ling, K.H. Mo, L. Qu, J. Yang, L. Guo, Constr. Build. Mater. 146 (2017)

13. H. Elçi, J. Clean. Prod. 112 (2016)

14. A.M.M. Al Bakri, M.N. Norazian, H. Kamarudin, C.M. Ruzaidi, Malaysian Univ. 
Conf. Eng. Technol. (2008)

15. N. Anting, M.F. M. Din, M. Ponraj, K. Jungan, S. Mat Taib, K. Iwao, S. Chelliapan, N. Ubukata, Malaysian J. Civ. Eng. 26 (2014)

16. A. Ahmed, U.H. Issa, Soils Found. 54 (2014)

17. L.S. Wong, S. Mousavi, S. Sobhani, S.Y. Kong, A.H. Birima, N.I. Mohd Pauzi, Measurement. 94 (2016)

18. K. Xia, Comptes Rendus Mécanique 342 (2014)

19. British Standard Institution, British Standard Methods of Test for Soils for Civil Engineering Purposes (BS1377, London, 1990).

20. The British Standards Institution, British Standard Code of practice for site investigations (BS 5930, London, 1999).

21. M. A. Mas, J. Monzó, Paya, L. Reig, and M. V. Borrachero, Institution of Civil Engineers, (2015).

22 British Standards Institution, British standard methods of test for soils for civil Engineering Purposes (BS1377, Milton Keynes, London, U.K. 1990).

23 A.K. Sabat, Electron. J. Geotech. Eng. 17 (2012)

24. C. Neeladharan, V. Vinitha, B. Priya, S. Saranya, Int. J. Innov. Res. Sci. Eng. Technol. 6 (2017)

25. J.A. Chen, Idusuyi, F. O, Int. J. Eng. Mod. Technol. 1 (2015)

26. S. Pourakbar, A. Asadi, B.B.K. Huat, M.H. Fasihnikoutalab, Transp. Geotech. 3 (2015)

27. G. R. otoko, I. F. manuel, I. S. chinweike, P. harcourt, Journal of Multidisciplinary Engineering Science and Technology (JMEST), 3(5) (2016).

28. Tg. Rani, C. Shivanarayana, D. Prasad, D. Prasada Raju, Int. J. Eng. Res. Dev. 10 (2014)

29. N. Ameta, A. Wayal, P. Hiranandani, Am. J. Eng. Res. 2 (2013) 